Article

\title{
From Needs to Rights-A Socio-Legal Account of Bridging Moral and Legal Universalism via Ethical Pluralism
}

Andrej J. Zwitter

Department of Legal Theory, University of Groningen, Oude Kijk in 't Jatstraat 26, 9715 EK Groningen,

The Netherlands; E-Mail: a.zwitter@rug.nl; Tel.: +31 503635991; Fax: +31 503637253

\section{How to Cite this Article}

Zwitter, A. J. (2013). From Needs to Rights-A Socio-Legal Account of Bridging Moral and Legal Universalism via Ethical Pluralism. Politics and Governance, 1(1), 74-91.

\section{Acknowledgement}

This Article was published by Librello, Politics and Governance's former publisher.

\section{About the Journal}

Politics and Governance is an innovative new offering to the world of online publishing in the Political Sciences. An internationally peer-reviewed open access journal, Politics and Governance publishes significant, cutting-edge and multidisciplinary research drawn from all areas of Political Science.

www.cogitatiopress.com/politicsandgovernance

\section{Editors-in-Chief}

Professor Andrej J. Zwitter, Faculty of Law, University of Groningen, The Netherlands

Professor Amelia Hadfield, Department of Psychology, Politics and Sociology, Canterbury Christ Church University, UK

\section{Managing Editor}

Mr. António Vieira, Politics and Governance, Cogitatio Press, Portugal 


\title{
From Needs to Rights-A Socio-Legal Account of Bridging Moral and Legal Universalism via Ethical Pluralism
}

\author{
Andrej J. Zwitter
}

Department of Legal Theory, University of Groningen, Oude Kijk in 't Jatstraat 26, 9715 EK Groningen, The Netherlands; E-Mail: a.zwitter@rug.nl; Tel.: +31 503635991; Fax: +31 503637253

Submitted: 26 November 2012 | In revised form: 10 May 2013 | Accepted: 15 May 2013 |

Published: 30 May 2013

\begin{abstract}
The question of the universality of human rights has much in common with the question of the universality of ethics. In the form of a multidisciplinary reflexive survey, the aim of this article is to show how human rights discourses derive from more basic principles related to basic needs. These needs are the universal grammar for moral principles, which will be distinguished from ethical norms. Ethical norms, I will argue, are rules that develop in social groups to put into effect moral principles through communicative action and therefore develop as culturally specific norms, which guide behaviour within these social groups. This will explain why ethical norms contain some universal principles, but are largely culturally specific. In order to shed some light on the universality debate, I will show how moral principles translate into ethical norms and might manifest through communicative action in human rights law. For this purpose the article develops a socio-legal account on social norm-creation that bridges moral universality and legal universality via ethical pluralism, which in effect explains why despite the universality of moral principles, the outcomes of ethical rationales can vary extremely.
\end{abstract}

Keywords: discursive action; ethical pluralism; human rights; moral universalism

\section{Introduction}

In many ways natural rights have found their way back into common discourse. Statements of politicians and even court decisions account for that. This trend parallels the belief that human rights are universal. Such a conviction is fundamentally rooted in the belief of an existence of universal moral principles. However, cultural pluralists reject the belief of universality of morals; their most lenient position is that, although morals are different all over the world, in discourse we might find some common principles on which we all can agree. This article aims to give a socio-legal account of these positions that bridges moral universalism understood in relation to basic needs and legal universalism based on universal agreement between states in an interdisciplinary manner. While the individual debates traced herein are quite well known, they usually take place apart from each other. This article tries to place these debates in a broader socio-legal framework functioning as a conceptional link. The argument that this socio-legal account puts forth is then that due to our commonness in needs and vulnerabilities we all share common moral principles (moral universalism); but due to different mechanisms to protect from threats to needs and to alleviate vulnerabilities, which developed differently within different cultures, ethical 
norms are not universally the same, but on the contrary are very different (ethical pluralism); eventually, through international ethical discourse states are able to negotiate norms that are universally valid on legal grounds based on the acceptance of all states (legal universality). In this manner, this essay creates a link between these three conceptions about universality versus plurality and thereby constitutes a reinterpretation of Thomas Paine's distinction between natural rights and civil rights adapted to a globalized world. The arguments will refer to advancements in cognitive psychology concerning empathy and will be placed in a socio-legal framework on social norm-creation.

Section 2 will use human rights to exemplify three things: (a) that human rights are not themselves universal moral principles, but are based on culturally specific ethical norms; (b) that human rights can only claim legal universality based on acceptance by states; and (c) that human rights by themselves have become a culture for human rights lawyers and activists. This results in the phenomenon that even within the same culture, human rights advocates have distanced themselves from the popular opinion of large portions of society and/or from politicians about what constitutes ethical conduct. Section 3 will then briefly elaborate on norms that some authors accept as universally valid and continue with the example of "the prohibition of torture". Building on Wittgenstein's conception of depth grammar, the cultural grammar underlying the very foundations of language, the article will explain how cultures give their own coloration to discourses, which leads to a differentiation between universal moral principles and culturally specific ethical norms (a distinction between morals and ethics) [1]. Based on psychology of human motivation (related to needs) and cognitive research on neurological foundations of language acquisition, empathy and moral development (i.e. mirror neurons), Section 4 will explain how social-norm creation can be seen from a socio-legal perspective. Section 5 will then develop the socio-legal account based on the case of the prohibition of torture. Eventually, this article will contribute to the larger debate with a structural explanation on how societies tend to re-evaluate already established ethical norms in the face of events with great moral impact.

Moral principles and ethical norms, be it their universal application, their ethnocentric roots or their cultural interpretations, are a product of an extensive canon of post-Enlightenment ideas drawn from a rich variety of sources. This article reflects on these sources and tries to revisit the salient parts of some of these ideas by tying them together into one larger account of social norm-creation. By having to draw on a variety of abiding debates and case material, exploring their inner logic, and testing them against their equally colourful background from which they derive, this essay obviously faces the challenge to revive well known themes without becoming to superficial, while at the same time drawing the bigger picture of how, in the author's account, societies come from a priori morals to human rights. Thereby, this essay essentially aims to reconcile the universalist with the pluralist worldview through the use of theoretical elaborations on language, empathy and social norm-creation. The here presented account is then one of how initially universal moral principles pertaining to the protection of individuals and of social groups from harm become culturally coloured and emerge as culturally specific ethical norms. These ethical norms can become universal again only through international consensus. At this stage these ethical norms have absorbed many culturally specific assumptions that their acceptance is often disputed. The overarching objective of this essay is to lay the groundwork for future questions in the study of politics and ethics that aim to go beyond the contemporary tendency of scholarship to give priority to certain ethical concepts such as justice, whilst ignoring the canon of other concepts such as beneficence, magnanimity, mercy etc. as well as the pertaining question of vices and evil in international politics.

\section{Non-Universality of Human Rights}

Let me now turn the attention to the legal debate about universality, specifically with regard to human rights. Although this generalizes the subject greatly, one can make the classic distinction between natural law and positive law with regards to human rights as well. Thomas Paine made the distinction between $a$ priori given natural rights of persons and of a posteriori given civil rights (read: human rights) when stating:

\footnotetext{
"Natural rights are those which appertain to man in right of his existence. Of this kind are all the intellectual rights, or rights of the mind, and also all those rights of acting as an individual for his own comfort and happiness, which are not injurious to the natural rights of others. Civil rights are those which appertain to man in right of his being a member of society. Every civil right has for its foundation some natural right pre-existing in the individual but to the enjoyment of which his individual power is not, in all cases, sufficiently competent. Of this kind are all those which relate to security and protection." [2]
}

In response to an attack on the principles of the French Revolution in the House of Commons by Edmund Burke, Thomas Paine formulated the first part of the Rights of Man. He postulated civil rights as having their basis in natural rights; but he was also clear that these rights may not be fully enjoyed unless supported and protected by the state. This perspective 
is very representative of the 'natural law branch' of legal scholarship, which assumes that humans are to the same extent entitled to the same rights. The natural law approach argues in different ways for a common morality that is enshrined either in human nature, human dignity, nature, or god given law, which in turn results in natural rights [3]. The natural law discourse is particularly tempting nowadays as it assumes a close connection to human rights. This is apparent in many writings and a very common statement is: "we are all humans thus we all have the same human rights" (for similar statements and annotations see [4]). The statement demonstrates how language is used to connect two concepts, which are not necessarily married, by bridging the logical gap between being human and having rights through attaching the label 'human' to rights. Such rhetoric can lead to a wrong explanatory mechanism of why natural rights may result in human rights. Paine's perspective is particularly valuable with regard to the social mechanism pertaining to security and protection. Paine's perspective is different from Henry Shue's consequentialist argument for universality that certain rights (three in his case, eight in the case of Talbot [5]) are prerequisites because they ensure the enjoyment of other rights and protect against standard threats [6].

To a large extent this concealed retreat to natural law via rhetorical logic follows the intuitive feeling that there is some commonness-a universal morality. Many contemporary legal scholars (particularly of a continental European legal tradition) have, concerning universality of human rights, assumed the perspective of legal positivism, since natural law is considered to be outdated [7]. On the other hand, one of the most common references of 'legal rationalists' to be found derives from Kant's categorical imperative in one way or the other. Legal positivism essentially states that law is distinct from morality as it is simply a result of a process rooted in the legal system. Law does therefore not derive its validity from being morally right or just, but from being the result of a correctly followed procedure. Hart strongly defended this position and the need for a distinction between 'law as is' and 'law as ought', trying to separate the legal sphere from the moral sphere. He reiterates his position by the help of two utilitarians, Austin and Bentham, who "insisted on the need to distinguish firmly and with the maximum of clarity, law as it is from law as it ought to be. This theme haunts their work, and they condemned the natural-law thinkers precisely because they had blurred this apparently simple but vital distinction" [8]. Even though one of the major works on legal positivism, Kelsen's Pure Theory of Law, is a tribute to Kant's Critique of the Pure Reason, Kelsen rejects what he calls empty formulas ('inhaltsleere Formeln') such as the categorical imperative and the golden rule as basis of a principle of justice, because these formulas make justice subject to what one is willing to accept for oneself [9].

However, the principle of justice, which is commonly filled with natural legal assumptions, always finds its way back even into positive law through legal principles and the margin of appreciation of judges. One could further argue that law, because it is a matter of social agreement (within the right procedures and ultimately also about the right procedures), is always culturally specific. Such an argument would make legal positivism a relative of moral pluralism. Nevertheless, the difference is that legal positivism can explain universal human rights by referring to its universal acceptance through ratification by states. This is quite important because it distinguishes morality from law and introduces the idea of a universal discourse, which can result in consent about the formulation of a treaty and in acceptance by ratification. The universality then results not from being universally true but from being universally accepted-a legal universality.

With regard to cultural relativism in legal discourses the following arguments can be seen as examples of the overall perspective on Non-Western critique of human rights law (for a very elaborate account on different arguments why human rights are a particularly Western concept see [10]). In Vedic and Confucian traditions, critics of universality of human rights contend that duties towards the group are more important than rights of the individual against the group. In other words, Confucian virtues of order, obedience, and respect for authority are seen as justly limiting human rights as a sacrifice of a few for the benefit of many [11]. The Singapore School on Human Rights does not reject human rights per se, but it rejects the Western values in them that derive from cultural and historical developments of Europe and the US. At the same time, the Singapore School criticizes the West for applying double standards and pursuing its own political and economic agenda in the fight for human rights ([12], pp. 36-37). Out of the desire to "Africanize" human rights, African states established their own human rights regime. The African human rights discourse as manifest in the African Charter of Human and Peoples' Rights is very explicit about collective rights of groups and peoples: Art. 18-family rights to protection, Art. 19-equality of peoples, Art. 20-right to self-determination, Art. 21-peoples' right to freely dispose of their wealth and natural resources, Art. 22-peoples' right to economic, social and cultural development, Art. 23right to peace and security, Art. 24-right to a satisfactory environment ([12], p. 93). In terms of mechanisms of community survival it reflects a complex of communal entitlements and obligations, which are grouped around concepts such as respect, restraint, responsibility and reciprocity [11].

Another non-Western approach would be the Islamic discourse on the universality of human rights, 
which can be divided into three branches: (1) one that sees Islamic law as the perfect protection against human rights violations; (2) another approach that is aware of the differences and claims impossibility of full compatibility; and (3) yet another approach that suggests the possibility of applying the concept of margin of appreciation, i.e. a measure of discretion allowing states to take into account particular national circumstances [13], in human rights law and also proposes applying the Islamic equivalent to this concept (welfare: maslahah) to mitigate between cultural differences (for more detailed elaborations see [12,14, 15]). Radical cultural relativism finds support in the second position: "Western condemnations of discrimination against women in other regions are said to reflect an insensitive, ethnocentric approach to rights issues, which is linked to cultural imperialism" [16]. One of the less obvious (but very important) differences is that Islamic law is a combination of individual duties and community duties (five pillars of Islam, e.g. charity enforced by a poor-due tax, zakat) and entitlements of classes (for zakat the destitute and needy) that try to ensure a stable society and not the assertion of individual rights and freedoms [17].

There is one particularly strong argument against the universality-of-principles perspective on human rights: what a social group perceives as right and wrong in terms of human rights might differ from universally accepted human rights based on different values that are applied in a local cultural setting. These values of the social group are derivatives of its own social and historical context. In this regard universality of human rights can thus only be understood as the consent of states as representatives of their citizen to be bound by certain norms. Different cultures, the argument continues, do not intrinsically nor inherently refer to a common conception of human rights but rather to what Donnelly alludes to as human dignity, which makes them only seemingly the same [18]. Using similar labels, such as morality and human rights or even the same term such as 'human dignity' does not necessarily result in a compatibility of the underlying value hierarchies that try to ensure need fulfilment of a social group and the protection from harm in different cultural contexts. Even within the same state the ordinary citizen and the human rights lawyer might come into dispute over human rights that are not in harmony with the moral sentiment of the public, as the following cases demonstrate.

As a concrete example of the difference between popular ethical intuition and legal argument serves the protest of politicians with regards to a decision of the German Constitutional Court that shooting down a plane which aims at a populated area would violate the individual right to life and human dignity of the passengers. The court defended its anti-utilitarian perspective with the argument that one could not assume that innocent passengers would consent to give their life for others just by boarding a plane [19] (see also [20]). Another example is the "Mauerschützen" trials (the Berlin wall shooting trials) in Germany. After the German reunion, the German Highest Court circumvented the prohibition of retroactive penal law by arguing that East-German soldiers, who shot people trying to cross the Berlin wall (before the reunification) and went unpunished in Eastern-Germany, violated law common to all nations. Obviously, this law was not common to all nations; thus legal scholarship (contrary to the general public) criticized the court of having brought back natural law into the legal positivist tradition of Germany and connecting it with human rights law through the backdoor of Radbruch's formula ([21]; concerning the natural law argument see also [22]). Eventually the European Court of Human Rights followed the German Highest Court in its opinion [23].

Yet another instance of how different national courts in comparison to the popular opinion might argue is the following trial, in which the German Highest Court came to a conclusion that was contrary to the popular moral sentiment. The Daschner criminal trial concerned the former deputy police chief of Frankfurt, Wolfgang Daschner, who threatened Magnus Gaefgen, the suspect who had already confessed to the kidnapping of a boy, with torture if he would not reveal the boy's location. In the criminal procedure against the deputy police chief, the court came to the conclusion that human dignity (Article 1 paragraph 1 sentence 1 German Grundgesetz) is an untouchable principle without exception, which corresponds with the absolute prohibition of torture of Article 3 European Charter of Human Rights [24]. This case resulted in a heated discussion about the permissibility of 'rescue torture', a variant of the ticking bomb scenario, among scholars, the German press and the German public [25].

All the above cases have in common that due to different conceptions underlying the same label ('human rights') a fierce disagreement within even the same state occurred. It seems that the legal conceptions underlying the argument of universality have changed to that extent that common moral sentiments cannot consent to the results of law application in extreme cases. The limits of a semantic incompatibility of human rights with general ethical beliefs become apparent in these cases. That the fault lines of this disagreement open up between the wider, not legally trained public, politicians with certain responses in mind, and human rights lawyers suggests that human rights have emerged as a fairly specific kind of ethical norms within a legal culture that does not always correspond with the public opinion about morality and by extension of how law should work. 
This is, however, not the whole story. People might disagree in these extreme cases where human rights seem to violate utilitarian moral logics, but such logics come under attack where the level of cruelty, the systematic nature of the deed and its proportions are clearer as with torture in Abu Ghraib and Guantanamo Bay. In other words, there seems to be some consensus concerning the existence of very basic moral principles. This is not to say that there is consensus on the justifications applicable to deviate from moral principles such as: what constitutes the greater good, avoiding a terrorist attack by retrieving information from suspects through torture or not living in a society in which torture is the sword of Damocles hanging over everyone's head who might be identified as a potential bearer of valuable information? The next section will discuss moral universalism and relativism to shed some light on what could constitute the universal core and what the relativist elements of human rights.

\section{Language and Morals}

One can distinguish between two contrary theoretical positions regarding ethical norms, moral principles and cultures which one can label 'radical cultural relativism' and 'radical universalism'. The former sees culture as the sole source of validity of a moral right or wrong, while the latter holds that cultural perspectives are irrelevant to moral validity as moral principles are universally valid [26]. The radical cultural relativist's main argument claims that there are no rights that everyone is entitled to equally because humans are different [27]. The following explanatory argument underlies this ethical relativism: people differ in their basic moral beliefs; "there are or there can be no value judgements that are true, that is, objectively justifiable independent of specific cultures" ([28], p. 782); "in every case the rightness of any act or goodness of anything for a member of culture $A$ is justified by reference to what in fact is considered right or good in culture A" ([28], p. 786). Radical cultural relativists, therefore, deny common values that all cultures share, such as human rights. In response Donnelly argued, that "if human nature were infinitely variable, or if moral values were determined solely by culture, there could be no human rights (rights that one has "simply as human being") because the concept of "human being" would have no specificity of moral significance" [29]. Radical universalism essentially turns these arguments around, claiming that all humans are the same and therefore the same moral principles apply to everyone. The reasons can range from natural law, to a Humean inherent moral sense [30], to rational Kantian reasoning [31], or combining moral sentiments with rational reasoning [32].

In between these two extremes, one can locate two branches of moral philosophy that argue for a middle path and agree on some degree of commonness: 'weak cultural relativism' and 'soft moral universalism'. Donnelly advocated weak cultural relativism as an explanation that integrates both the 'undeniable fact' of cultural relativism and the universality of some norms by resorting to the human rights discourse as follows:

"Rights held equally by all against the state, both limiting its legitimate range of actions and requiring positive protections against certain predictable economic, social, and political contingencies, are a seemingly natural and necessary response to typically modern threats to human dignity, to basic human values, traditional and modern alike" [33].

Donnelly's approach, which he later terms "functional universality" attributes universality of ethical norms to the fact that the same constraints are being posed to the individual in the modern state. Moreover, when using the terms 'human dignity' and 'basic human values' he assumes that there is indeed some commonness to be found. The mere fact that modern states pose similar threats does not yet mean that similar values are threatened. Thus, this perspective is only plausible if these similar threats are directed against similar values. This means a necessary presumption of same threats is that people are the same in what can be threatened in the first place. Earlier in his writings Donnelly, however, seems to suggest that the principle of human dignity is to some extent universal but realized in different ways [18]. This sociolegal perspective in his earlier writing does not come back in Donnelly's 2007 article The Relative Universality of Human Rights and the following debate with Goodhart, which discusses a wide range of different forms of universality (functional, legal international, overlapping consensus, anthropological, and ontological universality of human rights) [34-36]. However, exactly the commonness of human faculty is what seems to be the initiating factor for social normcreation as will be elaborated in Section 5 .

Soft moral universalism assumes that there are some basic moral principles that are shared by all cultures such as human dignity or the prohibition of murder, but also assumes that different cultures may apply or ensure these principles differently. When looking into diverse cultures at various points in times, some scholars found that there are some basic principles that where valid in all cultures. Gert and Lewis described a set of common moral principles one might regard as universal (and which will illustrate how the use of labels and categories leads to a semantic incompatibility, but not a factual one). Following Gert's account of universal moral principles there are ten norms the violation of which without justification is universally prohibited as immoral action (see Table 1). 
Table 1. Gert's ten universal moral principles [37].
1. Do not kill.
2. Do not cause pain.
3. Do not disable.
4. Do not deprive of freedom.
5. Do not deprive of pleasure.
7. Keep your promises.
6. Do not deceive.
9. Obey the law.
8. Do not cheat.
10. Do your duty.

Table 2. Lewis' illustration of the Tao [38].

\section{The Law of General Beneficence: 'I have not caused hunger. I have not caused weeping.' (Ancient Egyptian. ERE v. 478)}

3. The Law of Justice

a. Sexual Justice: 'Thou shalt not commit adultery.'

b. Honesty: 'Has he drawn false boundaries?'

(Babylonian. List of Sins. ERE v. 446)

c. Justice in Court, \&C.

5. The Law of Mercy [37]: 'You will see them take care of... widows, orphans, and old men, never reproaching them.' (Redskin. ERE v. 439)
2. The Law of Special Beneficence: 'Part of us is claimed by our country, part by our parents, part by our friends.' (Roman. Ibid. i. vii)

a. Duties to Parents, Elders, Ancestors

b. Duties to Children and Posterity
4. The Law of Good Faith and Veracity

'A sacrifice is obliterated by a lie and the merit of alms by an act of fraud.' (Hindu. Janet, i. 6)

6. The Law of Magnanimity: 'There are two kinds of injustice: the first is found in those who do an injury, the second in those who fail to protect another from injury when they can.' (Roman. Cicero, De Off. I. vii)
In a similar way, but more on the level of principles, Lewis distils eight principles of natural law, which he calls Tao, out of 119 examples (covering Australian Aborigines, Native Americans, Christian, Hindu, Chinese, Norse, Egyptian, Greek, Jewish, Roman, Germanic, and other traditions) that all cultures can account for without known exception (see Table 2).

The difference between Gert's and Lewis' account of universal norms might at first sight be interpreted as an argument against universality as such. Both try to prove the same point but come to different categories, which seem hardly compatible, because they categorize elements of the same object of inquiry ('social interaction') into other categories of moral principles. Gert formulates a prohibiting norm in the form of a commandment ("Do not cause pain!"). The physiological and psychological makeup of a human being that enables it to experience pain is implicitly assumed in both accounts. Lewis chooses not to formulate the norm in the form of a prohibition against the vice of cruelty, but in a commandment in the form of the virtue of general beneficence.

When looking closer, the laws of general and special beneficence describe Gert's first five norms by adding a psychological mechanism to it, namely that there is a difference between the compassion towards friends, family and strangers. Lewis' laws 3 and 4 do not appear in a special way in Gert's account as he does not reflect on the difference between the closeness of relationship in the first place. The law of justice relates to the principle 'obey the law' and 'do your duty'. And finally, good faith and veracity are reflected in keeping promises, not cheating and not deceiving. Magnanimity and mercy are, according to Gert, virtues that more describe the moral identity of a person than a moral principle ([37], pp. 76-79). Most of all, the reason for coming to different categories and labels might be that Lewis includes an element intrinsic to social behaviour that Gert blends out, namely the difference of compassion depending on the specific relationships involved. It is the phenomenon that in moral terms we do not only differentiate between me and the other but also between me, people that I am close to and the other. This is expressed by the law of special beneficence, which does not only relate to one's own preferences that we have in fulfilling moral obligations towards people who are emotionally closer to us. It seems to be also a bigger principle that a judging observer applies when (s)he sees a violation of moral principles regarding 
two actors that are either close to each other or not. This changes also the perception of severity of the breach of a moral principle [40]. The expression of special beneficence is not so much manifest in Human Rights Law (protection of the family and rights of the child merely acknowledge the specific importance of the family in social life and the increased vulnerability of children). It is, however, commonly found as an attribute in criminal law (e.g. different punishment for perpetrators who misused a relationship of trust). Also general beneficence exists regarding people that do not belong to the in-group quite commonly, for example as the principle hospitality in international legal discourse since Vitoria [41]. A modern view of Human Rights and particularly the concept of the Responsibility to Protect seem to also confirm growing international acknowledgement of general beneficence not only as a moral but also as an emerging legal duty.

Looking at common principles it is immediately apparent that (1) all principles mentioned by Gert and Lewis relate to social interaction, which is also the field of culture, and that (2) most of the principles mentioned relate directly or indirectly to the causation or the prevention of harm. Concerning (2), Linklater found that the principle of harm follows similar narratives across cultures because of the universality of the human condition to experience pain, which puts cruelty, i.e. causing harm without justification and simply for the sake of making someone suffer, to rank highest in the vices one can commit [42]. Harm and multiple general forms of how it can be inflicted through commission and omission reside in the psychology and physiology that compose together the human condition and its ability to experience suffering.

Next to that, some norms shape a basic structure of what communities in general need to be able to survive as communities (Gert: 6-10; Lewis: 2, 4, 5, $6)$. Norms such as veracity and justice are considered universal, not because they are relevant for individual survival, but for group survival. Social groups require some degree of trust and/or control to benefit from the advantages of cooperation among its members.

If the object of inquiry changes only marginally, it can happen that many implicit assumptions change as well or are added. Let us assume for now that the norm of general beneficence is based on the same assumptions as the prohibition of causing pain, namely the physiological and psychological makeup of a human being's ability to experience suffering. If we compare this norm with its equivalent norm in the Universal Declaration of Human Rights (UDHR), we find in the latter that many more assumptions are tacitly added: "No one shall be subjected to torture or to cruel, inhuman or degrading treatment or punishment" (Article 5). The basic assumptions that make the breach of this norm possible are the same (the human ability to experience pain). The difference lies not in the offence but in the formulation of the Article 5 and the logic of the UDHR as such. General beneficence and the prohibition of causing pain concern a perpetrator and the offence, and are valid independently from the culture in which they happen (as long as we do not include justifications). These general moral principles derive directly from a violation of human integrity. Therefore, they do not assume a conception of individual rights and freedoms or, for example, structures where norms oblige or give rights to communities instead of individuals. That means they do not contain secondary (executive) norms of how the violation relates to the victim with regards to rights. They only relate to the perpetrator in the form of a duty. Compliance mechanisms are also omitted. In the UDHR's view "no one" refers to an individual right of a subject to such a treatment (which is more clearly expressed in Article 2: "Everyone is entitled to all the rights and freedoms set forth in this Declaration..."). Thereby, the same norm implies much more in the latter case by adding the concept of entitlement. It additionally tacitly assumes that the same human is equipped with rights and freedoms that stem from its individuality. Thus, the shift from obliging the duty bearer to give rights to an individual is a step that changes the object of inquiry from a moral principle stemming from basic physiological and psychological experiences of pain to the rights of human beings as individualized entities. It furthermore assumes that humans are entitled to exercise these rights and freedoms against a state entity with corresponding duties.

Therefore, in the light of the discussion above one can see that semantic incompatibilities do not necessarily result in factual incompatibilities concerning the protected value. However, as soon as additional assumptions (about the rights/duty relationship between rights-holder and duty-bearer; the relation between state, groups and individuals; the forms of suffering; the relationship between in- and out-groups) are implicitly introduced, one creates norms that presuppose certain cultural-normative structures. This is what always happens in social norm-creation and which creates the impression that there is no universality. Nevertheless, the underlying reason for creating the norms "Do not cause pain"/General beneficence/ Article 5 UDHR is originally the same and universalto protect people from harm. Thus, language has two effects: (a) using different categories and labels seemingly leads to an incompatibility based on semantics; and ( $\beta$ ) attaching tacit procedural and cultural assumptions leads to a real incompatibility. The next section differentiates between principles that can claim universality and the tacit procedural and cultural assumptions leading to culturally specific ethical norms. 


\section{Cultural Specificity of Ethics}

Since Maslow many scholars have attested that needs can create an impetus for human motivation (see for example [43-45]; [46]). One can essentially summarize that when people feel that their needs are threatened, this dominates their behaviour. My hypothesis in this regard is that the violation of fundamental needs leads people to identify moral principles. I use the term 'fundamental needs' to avoid the postulate of a biological essentialism, which would be caused by using the Maslowian term 'basic needs'. Maslow himself doubted that the hierarchical structure of needs reflects an order of importance of needs to the individual considering the fact that people go on hunger strike for their beliefs, i.e. are willing to risk physiological (basic) need fulfilment for psychological or transcendental needs [43]. 'Fundamental needs' mean to reflect the fulfilment of needs necessary to human faculty and without which life cannot thrive sustainably. In this sense transcendental needs (the need for an overarching framework that helps the individual to make sense of the world) are just as fundamental as the need for food, shelter and love. With the inclusion of transcendental needs one however includes philosophical frameworks, such as religions which are highly culturalized. Fundamental about it is then not the specific world view itself, but the need for such a world view whatever shape it might take (philosophy, religion etc.). One experiences this fundamental nature of transcendental needs when ideas and events cannot be explained by one's current world view and thus threaten the very fabric of one's sanity if one does not modify her/his world view.

Therefore, although the violation of fundamental needs is universally comprehensible in the same way, different mechanisms evolved in different cultures and social groups to ensure the fulfilment of these needs leading to a differentiation of expression of safety needs. Furthermore, higher value is attributed to value categories of subsistence of fundamental needs than to object categories that ensure survival to a lesser degree. These value categories of subsistence differ from culture to culture because they are based on different forms of survival. An example can illustrate the basic problem with regard to different value categories of subsistence and how it links to fundamental physiological needs: Stealing is forbidden in every culture. However the punishment for stealing varies. Stealing a cow in Western Europe nowadays might be seen as a petty crime punished with a relatively low sentence in comparison to the punishment that would result from the same act in a Muslim South Sudanese herding community (e.g. cutting off limbs) [47]. The difference in the punishment can be explained by the difference in what a cow means for the fulfilment of fundamental needs in one or the other community and culture. Thus, the same object (the cow) falls in the South Sudanese case into a value category of subsistence higher in the value hierarchy than it is placed in Western European cultures, although all do agree that it is a wrongdoing. Stealing a cow in Western Europe threatens the survival of the community less than in a South Sudanese herding community.

Cultural specificity is also reproduced in language. Some philosophers see herein an absolute hurdle. I will, however, elaborate that there are common denominators that allow overcoming this problem. Hudson's example of a small party of Martians coming to earth telling people what they ought to do illustrates the argument of some philosophers that we would not recognize an alien moral discourse as moral discourse, because the depth grammar of Martians would be fundamentally different to ours. According to Wittgenstein's theory of surface and depth grammar, language is woven into our lives and our culture. Therefore, the argument continues, we would not understand the depth grammar (telling us that if "x is red" one assumes that $x$ is an object with the physical attributes of 'red' that are visible to the normal sighted) underlying a Martian moral discourse [48]. My argument is that although language is woven into life and by extension into culture, the ultimate determinant and presumption of language is social interaction and therefore life itself. If moral is "what prevents harm to life", then one assumes that "harm to life can be caused by depriving life of fundamental needs". This is universally valid to all forms of human life and alien life to the extent of the similarity of fundamental needs and under the condition that the Martians possess the faculty of rational reflection.

Without a social counterpart language is not necessary and without the concept of life morality has no meaning in a discourse. This becomes evident when trying to come up with examples that try to disprove this assumption, e.g.: what is the moral property of disassembling an inanimate object that nobody is emotionally attached to and that serves no purpose to individuals and or social groups? This question becomes a moral question only once a sentient being fosters any kind of relationship to that object. The moral question becomes then whether the effect of disassembling the inanimate object leads to negative effects for the sentient being or a group. Most basic and thus universally understandable moral discourses can therefore be said to have at least 'life' as the universally common reference point, and in their prescriptive form the prohibition to harm life by prohibiting privation of fundamental needs necessary to sustain life. This means that if the Martian discourse was indeed about morality, then 'life' and the violation of it through causing harm would also feature in their moral discourse as a reference point, 
at least when talking about their most fundamental moral principles. Because we share this reference point, we would recognize their discourse as a moral discourse notwithstanding that we might disagree about the outcome of their ethical reasoning. Suggesting that moral discourse can ultimately (with regard to the reference point 'life' and by extension fundamental needs) always be recognized as such does not imply that all facets of a Martian ethical reasoning would disclose themselves to our comprehension. Because of a different depth grammar we might be unable to recognize a Martian moral discourse with regard to cultural specificities (e.g. if there were no concept of property in Martian culture, there would be no concept of stealing). Parallel to the punishment of theft of a cow in the South Sudanese herding community case, the elaborations on depth grammar also help to distinguish ethical norms from moral principles. The moral principles recognizable in a Martian discourse would be those that relate to harm by depriving of fundamental needs in various derivative forms of action (e.g. the act of stealing what someone needs to fulfil fundamental needs). The ethical norms reflect the culturalized specificities of social interaction, compliance mechanisms, ways in which a group ensures that fundamental rights are protected, and the hierarchy of values that determines the proportionality between violation of a prohibition, appropriate defence against such a violation and punishment. In the South Sudanese case ethical norms would be the value that livestock represents, the punishment attributed to stealing livestock, and the enforcement mechanisms attached.

I suggest that the more a moral discourse diversifies and departs from the common points of reference 'life' and fundamental needs, which make life possible and sustainable, and moves on to culturally coloured specificities of social life (diminutive derivations, e.g. social integrity, honour, property, importance of family, etcetera), the more depth grammar makes different cultures unable to recognize that the other's moral discourse and ethical reasoning is based on the same moral principles. The same mechanism of cultural coloration would make moral discourses between cultures that recognize different value hierarchies on top of the commonly shared value of life potentially incompatible. This becomes particularly apparent when looking at the order of value hierarchies. The question "is it justifiable to kill, inflict physical or psychological pain, offend or not to do anything if one's honour is violated?" results in different answers depending on the culture that is asked. The social mechanism of honour developed in some societies as a social mechanism to prevent crimes, while in others to protect one's honour was not necessary. This can be explained by evolutionary psychology: "A key element of cultures of honor is that men in these cultures are prepared to protect with violence the reputation for strength and toughness. Such cultures are likely to develop where (1) a man's resources can be thieved in full by other men and (2) the governing body is weak and thus cannot prevent or punish theft" ([49], pp. 48-49,51). To see honour as a value embedded in the social context helps understand how depth grammar might prevent members of one culture from understanding the actions of another culture as ethical.

How the respect for the other is expressed takes an even stronger cultural coloration. A female American student accompanying her professor on a field research through Islam expressed on one occasion her anger about an Islamic scholar they interviewed, because he would not even have the audacity to look in her eyes when talking to her. Her professor, familiar with both cultures, explained that the Islamic scholar, in accordance with his cultural expression of honour, would have dishonoured her by looking into her eyes [50]. In traditional Japanese culture honour was of highest importance and connected strongly with loyalty. For example, the Hagakure (the code of the samurai) describes how 36 samurai wanted to give their lives (seppuku) to honour their deceased master and show their loyalty. The clan leader, Mitsushige, heard of it and issued a decree that seppuku to show loyalty beyond life would be dishonourable and disloyal [51]. If such abiding loyalty as a value is alien to another culture, it has a hard time understanding the ethical rationale of the 36 samurai and it might simply call it craziness. Loyalty and subordination to superiors in traditional Japanese culture, however, were the foundation to the functioning of this society. Loyalty was not blind, but it also demanded from the samurai to tell his master if he was wrong, even if the samurai would be punished for it. In that way, the values of loyalty and courage to do the right thing enabled stability of the societal structures, which is why loyalty and courageous integrity cannot be separated from each other in the Japanese context without having destabilizing effects on the social system. This further indicates that fundamental needs of life might be at the centre of moral principles, but also that the functioning of the social system and the survival of the social group are at the heart of ethical reasoning, bearing the distinction between the two in mind.

As one can see with the example of honour, the role and place of values in the value hierarchy of a society enables its members to make conscious choices about moral questions concerning the rationale of their deeds in accordance with what the society would accept. This hierarchy of values is inherent in all principled moral arguments, and also in the previously discussed value of the prohibition of torture. The Human Rights Committee made the value 
hierarchies that guide the logics concerning torture explicit in is General Comment 20 on Article 7 International Covenant on Civil and Political Rights (ICCPR):

"The text of article 7 allows of no limitation. The Committee also reaffirms that, even in situations of public emergency such as those referred to in article 4 of the Covenant, no derogation from the provision of article 7 is allowed and its provisions must remain in force. The Committee likewise observes that no justification or extenuating circumstances may be invoked to excuse a violation of article 7 for any reasons, including those based on an order from a superior officer or public authority" [52].

The only reason of why human rights treaties were established in this way was given in a very short sentence in General Comment 7: "Its purpose is to protect the integrity and dignity of the individual" [53]. What remains implicit is the reason why dignity trumps life concerning torture in all circumstances. For finding out what reasons could be put forward, one would have to study the relevant case law and the materials to Article 5 UDHR and Article 7 ICCPR respectively.

We have now established that the norms we discuss in ethical discourse are culturally specific expressions of moral principles coloured by the depth grammar of a specific culture, which I call 'ethical norms'. I refer to 'moral principles' as those that can be considered universally common to all people and universally recognized as belonging to moral discourses - the tacit presuppositions of life itself, i.e. the ability to suffer (physiologically, psychologically or transcendentally) and to die or to lose the will to live as a cause of deprivation of fundamental needs. As soon as language is involved, moral principles become immediately tainted by cultural specificities, the order of values in the value hierarchy, by assumptions about how a social group ensures its survival, and by the relation between rights and duties as well as between individuals and the social group.

Habermas' term of discourse ethics takes a similar meaning with regard to ethics in the sense of a result of communicative action on which discourses are superimposed. Habermas assumes that moralities coincide because linguistic action is the source of and the solution to mutual vulnerabilities of socialized persons. In a discourse, the more exacting form of communication, he sees the potential of universalizing moral principles beyond the provincial limits of particular forms of life [54]. Habermas himself calls this a scaling down of the categorical imperative to a universality agreeable to all parties in the discourse (a biggest common denominator) ([54], pp. 201-202).
However, Habermas' argument of an agreeable universality works only, if one assumes that, as for example concerning human rights, there is a common denominator such as found in a priori existent moral principles deriving from fundamental needs. Because under the conditions set forth by different cultures to ensure these principles for the society in manifold ways, language has two more effects: $(Y)$ it connects ethical discourses and makes them potentially compatible within the same social group that shares the tacit cultural assumptions; $(\delta)$ it also separates different cultures from each other because they do not share these assumptions and the depth grammar would indeed result in the Martian dilemma. If there were no common moral principles, different cultures might try to negotiate, but they would never find a common ground. That agreement about human rights is possible, is the effect of a priori existent moral principles that derive from the human condition and fundamental needs.

In summary, a priori universality of the moral principles is given only in an early stage of when the moral norm is identified. This a priori universality derives from the human condition of being able to experience pain and suffering (through the privation of fundamental needs) and ultimately to die. After that initial stage of identifying the relevant moral principle, ergo as soon as discourse starts, language attaches many cultural specific elements to these principles. Most of them remain tacitly assumed. Furthermore, executive norms are attached to ensure compliance with the norm. These executive norms incorporate societal structures and the respective hierarchy of values. Once we reach this stage, we find a fully developed ethical norm as demonstrated with Article 5 UDHR in the previous section. This section used the concept of honour to explain the value hierarchies that are implicitly attached by cultures. It showed that these assumptions remain just as implicit in the Human Rights Committee's General Comments concerning torture.

The next section gives a sociological account to social norm-creation and continues on to a different form of universality (through universal acceptance-a posteriori) that can be achieved through international discourse-legal universality.

\section{Connecting Needs, Empathy and Morality}

With regard to depth grammar one might raise the question of what are, as Wittgenstein calls it, the tacit presuppositions of life and culture in moral discourse ([55], p. 197). Being part of the language game, such tacit presuppositions are assumptions of cognition that do not need to be expressed in order to be understood. Describing the scene of a patient and a doctor Wittgenstein explains that depending on whether 
it is a scene in a play or a psychology book our understanding changes: "If this experiment were described in the same way in a book on psychology, then the behaviour described would be understood as the expression of something mental just because it is presupposed that the subject is not taking us in, has not learnt the replies by heart, and other things of the kind" ([55], pp. 179-180, Section V). In similar terms when talking about ethics tacit presuppositions are constantly present, those about what constitutes life and those about what constitutes the norm in a culture. E.g. for stealing a cow his limb was cut off. The tacit presupposition of life is twofold in this case; both the cutting off of the limb is an infringement of life, and so must be the deed of stealing for which the retribution was cast. The tacit presupposition of culture in social life is the proportionality of the retribution in relation to the deed, the value hierarchy that relates to stealing of a cow and cutting off of limbs, and the assumption of an ethical system of norms regulating both the idea of property and the relation between actors. These tacit presuppositions thus rest on assumptions connected with the object of investigation, and ethics is the language game to form rules based on the tacit presuppositions of life and culture.

One tacit presupposition is revealed by the use of the word 'good' in all discourses. 'Good', or as Warnock translates it "human happiness or interests, needs, wants, or desires" ([48], p. 59), is obviously something that all moral discourses are concerned with. The tacit presuppositions we do all have in common is the fact that life in order to be sustained requires the fulfilment of fundamental needs. Another tacit presupposition of moral discourse is the fact that life can only be sustained in social interaction, which happens among humans to a large degree through speech-acts. Thereby, language becomes indispensable for the creation of a complex of moral principles, ethical norms and value hierarchies.

In terms of social norm-creation, if there were no conception of the wrongness of depriving somebody of his life without justification, human life would be without protection and open to attack any time. Since human life is, however, not possible without mutual social exchange, i.e. a society of humans, trust of not being killed by anyone randomly is a prerequisite of any society. Furthermore, since social norm-creation is a social process and the human being is socially embedded and dependent on the other members of the group, one possible justification of killing is logically when the existence of the larger group is at stake. The continuation of human existence in a society therefore requires the right to exist as a norm within this society. Likewise the society will claim a right to existence and therefore self-defence against external threats as well as individual members threatening the social structure that ensures survival.
In order for a group to survive, the first principle of the preservation of life is not to murder any member of the group without justification. This does, however, not preclude that value hierarchies might differ from culture to culture and that the values inherent in the justifications for killing a member of the group might differ.

How does social norm-creation relate to fundamental needs? With regard to social interaction one can postulate the following three points:

a) Actors derive moral principles (primary norms) from the violation of tacit presuppositions of life itself reflecting the fulfilment of fundamental physiological, psychological, and transcendental human needs.

Why would actors derive moral principles from violations of tacit presuppositions of life? From Adam Smith's [32] elaboration on moral sentiments based on sympathy to modern neurological and cognition research, many scholars agree that humans are equipped with moral faculty based on empathy [5659]. There is increasingly evidence that mirror neurones are responsible for empathy. Mirror neurones are neurones that fire when an individual acts and also when it observes action. Interestingly, originally attributed to the acquisition of both language and grammar, mirror neurones seem to be also largely responsible for empathy with the suffering of others and the imitation learning of moral principles as well (see for example $[60,61])$. In layman's terms, observing the suffering of others results in mirror neurons firing in the brain of the observer and thereby resulting in empathic compassion.

b) By abstraction based on these higher ranking principles (a) a group can envision certain actions as threatening to its own existence, which leads the members to engage in ethical discourse and to formulate prescriptive norms (e.g. protection of life, prohibition of harm, prohibition of stealing).

It is only natural that within social groups the drive to avoid both direct and indirect experience of harm will result in the exchange of opinions on how to achieve this. This results in what Habermas terms 'discursive action' trying to formulate principles of harm prevention. At the same time, how to ensure the preservation of life and the fulfilment of needs would strongly depend on how groups learned to survive together efficiently. This can be different based on the value categories of subsistence present in a culture resulting by and large from different cultural systems and technologies of production, the availability of sources of need fulfilment (food etc.), and the form of government and procedural order guiding the society's dispute settlement and norm enforcement. Therefore, one would learn different ethics in one culture than in another.

c) In order to protect moral principles (a) through 
these ethical norms (b) from future violations the group creates secondary norms ensuring compliance, i.e. norms that regulate the relation among individual members and between the group and its individual members (in the form of obligations or rights of the group and/or of the individual).

Eventually, discourses about human rights have long ago transcended the nation state through globalization, informal pressure by non-state actors with the aim to protect human rights and through states agreeing upon common laws in the form of international covenants on human rights. This universal agreement was already discussed above. But now it becomes apparent that the moral a priori universality in this last stage has diminished and made room for a legal a posteriori universality based on the international discourse between states. In this last step, as observed above with the Gaefgen torture case and the plane shooting debated in Germany, when states agree upon principles to become international law, there seems to be a disconnect between the moral sentiment of the public which remains in its own sphere (national, sub-national, local). States will have to trade off cultural specificities that are unique to the cultures they encompass in order to make agreement possible. This compromise might be between local cultural values and values accepted in international law either concerning mechanisms of ensuring survival (such as the role of the individual vis-à-vis groups and vis-à-vis states), or concerning the content of a norm in relation to justifications and aggravations.

The Kantian idea that morality strives for the highest good, which is an immanent and transcendent, but necessary and therefore possible object of volition [62], as Kohlberg interprets, has its own autonomous sphere. That means that a moral argument is distinct from other forms of argument as it uniquely establishes the tacit presupposition, which by the very nature of moral discourse asks questions about the relation between sentient beings and the effect of an event or act on their fundamental needs, at the same time with relation to the individual as well as to the social group. The question "Is it morally right?" [54] as Habermas puts it or the Kantian "What ought I to do?" has its autonomous sphere, if we can agree that morality is ultimately and minimally always about the reduction or prevention of harm through any privation of fundamental needs. This makes the discourse about morals recognizable for every culture, but not at the same time compatible, because the outcome of how to ensure moral principles needs to be formed along the lines that societal and cultural specificities require. Looking from this perspective back at Habermas' discourse ethics, it appears that the process of ethical norm-creation does not necessarily happen in a rational act of the individual moral agent but is rather the result of discourse among the members of a social group. The perspective of the social construction of ethical norms based on universal moral principles deriving from a discourse that acknowledges fundamental needs of the individual as member of a group as well as the group's overall needs thus leads to highly specific and culturally coloured ethical norms that contain: compliance mechanisms, justifications for violation, and aggravating elements (circumstances under which a violation is worse).

This then seems to also put into perspective that the argument that liberty in the form of individual autonomy constitutes the basic principle of morals is a highly culturally embedded argument (see for example $[63,64])$. Because individualistic liberty and rights are but one way of ensuring fundamental needs, another would be via group obligations towards the individual in mutual correspondence with individual duties towards the group. This has been illustrated with the non-Western critique to Human Rights above. Thus individual liberty is just one form of ensuring basic moral principles and not a basic moral principle by itself. It is an ethical norm, more exactly an executive norm, describing the relation between members of the community and the community itself, because it is a culturally specific mechanism that derives from the value hierarchies the community established. Following this perspective allows for natural law and positive law to exist in parallel as long as natural law remains a subject of need fulfilment and harm prevention, and positive law belongs to the area of ethical discourse about secondary and executive norms, i.e. culturally specific mechanisms to ensure these basic principles.

Figure 1 illustrates the here presented account of bridging moral universality and legal universality via cultural pluralism: the path from an offence against an individual or a group of individuals, via identification of the associated moral norm in different social groups (local and national), the attaching of culturally specific elements (compliance mechanisms, justifications and aggravating factors), which results in ethical norms and the negotiation on the formulation of ethical norms internationally and the necessary trade-offs to come to an agreement. In between the boxes the mechanisms empathy, national/local discourse and international discourse that have been discussed above are indicated.

International agreement found that the prohibition of torture would have to become an absolute prohibition in order to protect the inviolable dignity of the human being. This led over the years to many different international laws (Article 5 UDHR 1948, Article 7 ICCPR 1966, Torture Convention 1984, Art. 7(1)f, 8(2)a/ii Rome Statute 1998). If this happens in a public debate and the national authorities feel 


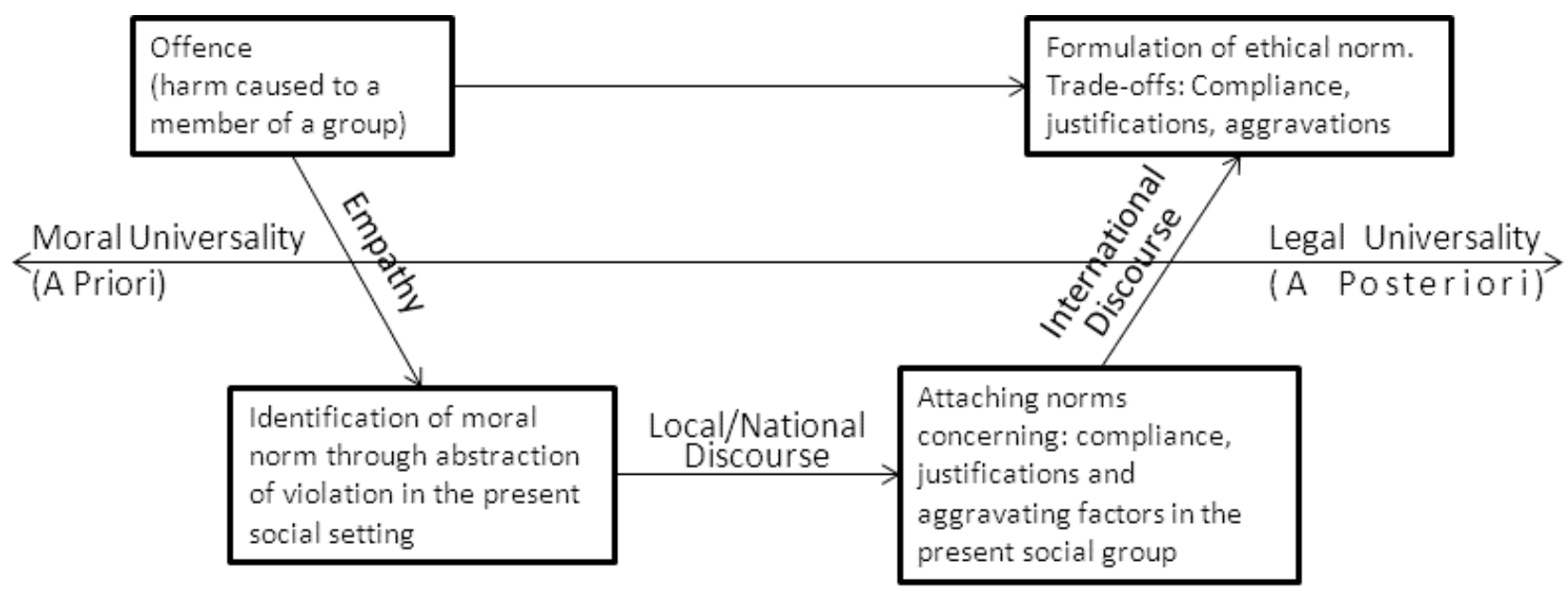

Figure 1. Socio-legal framework bridging moral and legal universality via cultural pluralism.

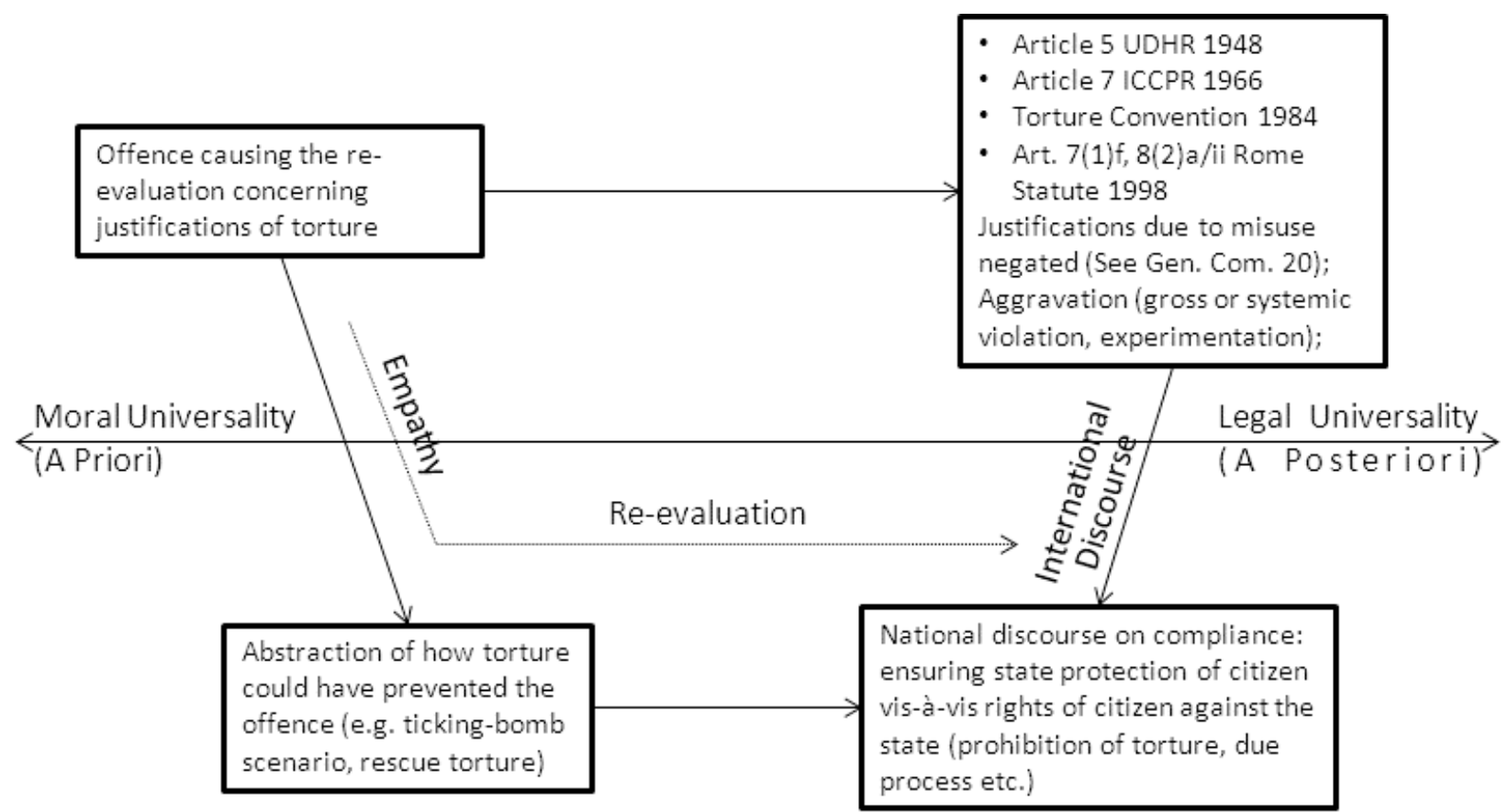

Figure 2. Process of re-evaluation of torture regulations within the socio-legal framework.

obliged to continue to comply with international law previously accepted, they will face criticism from those who support 'rescue-torture'. If national authorities would follow the rescue-torture argument, they might detach themselves from the international norm. This would cause a debate with the adherents to the internationally agreed norms (both within the country and internationally). In other words, social norm-creation might result in a re-evaluation in extreme circumstances and in effect might reduce de facto legal universality.

The Daschner case caused the German society to re-evaluate the value hierarchy between the right to life (of the kidnapped child) and torture (or the threat of it against Gaefgen to surrender the details of the child's whereabouts). Furthermore, among the population the justifications of rescue-torture were discussed. If the society would have had the choice and the state no pre-existing absolute obligations, rescuetorture might have become a reality. A similar path can be observed in the United States within governmental circles, where after the tragic events of $9 / 11$ the justifications concerning torture were indeed reevaluated. This came to be known as the infamous torture memos and John Yoo's legal justifications for why harsh interrogation techniques would not amount to torture. It resulted in an international debate led by governments, the ICRC, NGOs, and human rights activists, who invoked international law and finally led to a course correction of the United States. In this 
case the course correction came by pressure from adherents to the international norms but not without causing other governments (among others Poland, Romania, Germany) to tacitly support the United States' practices as became evident in the Council of Europe report "Alleged Secret Detentions and Unlawful Inter-State Transfers Involving Council of Europe Member States" [65]. This reduced the a posteriori legal universality. Figure 2 illustrates this within the elements and processes of the account given in this essay.

This socio-legal account of universality of moral principles and cultural specificity of ethics suggest something else: despite the fact that a priori moral principles are universally the same, cultural colorations and re-evaluations can lead to the modifications of value hierarchies (for example from human dignity to homeland security) that can not only weaken $a$ posteriori legal universality, but in extreme circumstances even reverse the outcome of the ethical reasoning. This means that moral principles are less determinative of the outcome of ethical reasoning than the respective value hierarchy applied. As paradox as this sounds, one has to consider that the hierarchy of values determines the proportionality between deed and response. Thus, while the moral principles remain the same (e.g. 'do not unjustifiably cause harm'), the justification might just tip the scale in favour of arguing that a certain harm caused is justified. Practically this can mean in the case of torture that if in ethical discourse issues such as homeland security, individual liberty, the hypothetical threats of terrorism, and other similar arguments become stronger, value hierarchies might just be modified enough to blur the lines between interrogation and torture so much that we can no longer speak of an absolute prohibition in the sense of an $a$ posteriori universality. Figure 2 above shows how reevaluation of justifications can diminish the a posteriori universal validity of the prohibition of torture.

\section{Conclusion}

This article demonstrated that moral universality and legal universality interact with ethical pluralism. Concerning moral universality, what connects human beings is the principle that fundamental needs of individuals and of a social community need to be ensured and that harm to them needs to be prevented. The universality of this moral principle is only inherently present and hardly observable as universality ends as soon as communities start a discourse on the different ways in which they want to ensure these needs. Depending on the culturally specific mechanisms (such as the role of duties and/or rights of the group and/or its individuals) and the diverse value categories of subsistence, their hierarchy and the weight of values are different. I called them culturally specific mechanisms, since they pertain to social groups within which through custom, practice and discourse certain enforcement mechanisms developed. This might call for further research on how cultures and practices relate to social mechanisms of normcreation and to the elements of subsistence (farming, herding etc.) certain social groups have adopted. There is no doubt that globalization and the interaction between different social groups, just as much as the reassembling of social groups for different purposes (economic, religious, etc.) over the course of human history makes this task tremendously difficult. This is particularly challenging also because every newly formed social group will develop new customs pertaining to its purpose and therefore new ethical norms.

From this perspective, what pluralist human rights debates actually criticize are not the basic moral principles underlying human rights but (1) the culturally coloured way human rights try to achieve the safeguarding of fundamental needs and (2) a certain hierarchy of values (and their weight) which is implicitly introduced. This can lead people to reject human rights because they feel that they do not fit the system of enforcement mechanisms, which their own social group has developed and to which they have grown accustomed. Thereby Donnelly's "functional universality" gets another turn. According to the elaboration above, moral universality does not primarily derive from the same constraints and the ways of how to deal with these constraints. It derives from the most basic reference point of moral discourse being 'life' and the physiological, psychological and transcendental unity of human faculty with its intrinsic capability to suffer and to have empathy with the suffering of others through the effect of mirror neurones. This potentially connects every culture due to the use of the same reference points: human life, fundamental needs, and corresponding violations. These same reference points make a global discourse about common ethical norms possible.

I have therefore argued for a distinction between universal moral principles and ethical norms. Moral principles are universal on the basis of the principal ability of all humans to physiologically, psychologically and transcendentally experience suffering. Ethical norms are culturally specific because, as soon as social discourse engages with an offence, elements typical to the social group are naturally added through depth grammar and through discussing enforcement mechanisms, justifications, and aggravating factors. Values and value hierarchies derive from the categories of objects that a group requires for subsistence and from the societal norms that ensure an efficient social interaction. That means cultural values also become a subject of ethics, not because they represent 
fundamental needs of individuals, but because they ensure these fundamental within and for a community. The role of honour was used as an example in this respect.

Universality can again be reached in the form of legal universality, which is dependent on universal agreement. That the negotiations and compromises which led to the formulation of the "universal" Human Rights documents took place particularly among Western powers is no legal argument against legal universalism. However, it is a strong political argument that derives from the fact that other states joined these treaties later and without the chance for a renegotiation in relation to the ethical norms of their own cultures. From their perspective, scholars rightfully argue that human rights contain particularly culturally coloured secondary norms derived from the ethical discourse of certain (mostly Western) social groups. They can never be factually universal as long as different social groups have different value hierarchies and diverse mechanisms of ensuring subsistence of individuals and groups. This socio-legal account presented here does not only explain the process from moral universality via ethical pluralism to legal universality, but also elucidates how and why there is just as much disagreement as there is agreement on the universality of human rights. Furthermore, it explains how (and to some degree why) societies constantly re-evaluate their relation to these universally agreed norms and why universal moral principles are no guaranty for similar outcomes of ethical questions.

This essay raises as many questions as it tries to answer. It shows that there is a strong relationship between culture, traditional elements of subsistence of social groups and social norm-creation. How this relationship exactly works, however, still remains open for further research. In addition, the socio-legal framework presented would require further research in the nature of the offences that trigger re-evaluation of established norms. This undertaking might well benefit from cognitive psychological research on morality and decision-making. As mentioned in the introduction, this article also wants to prepare the ground for further theoretical investigations concerning an extended canon of ethical concepts commonly derived from virtue ethics. C.S. Lewis' description of universal moral

\section{References and Notes}

1. Usually, the distinction between 'ethics' and 'morality' is rather unclear. Mostly 'ethics' is regarded as the philosophical study of morality, and morality is the issue of everyday practice. See, for example: Gert B. The Definition of Morality. In: Zalta EN, editor. The Stanford Encyclopedia of Philosophy. Summer 2011 Edition. Available from: http://plato.stanford.edu/arch principles has already highlighted universal norms (magnanimity, beneficence, veracity, good faith, and mercy) that hardly feature in contemporary debates in political philosophy, law and international relations. Theoretical investigations concerning the universality of virtues might shed even more light on the socio-legal function of ethics and the workings of ethical reasoning. Additionally, a virtue ethics perspective on international politics would also ask for the study of what constitutes vices in contemporary legal and political discourses on ethics.

For the practice of international politics the discussion in this paper shows that the current human rights system (that includes social, economic, cultural, civil, and political rights) as well as its enforcement mechanisms are indeed not at all suited to accommodate differences between different legal cultures and approaches to compliance with prohibitions against harming the survival of individuals and groups. The mere fact that the conception of human rights focuses on rights of the individual against the state ignores all other possible combinations of individuals, groups and states on the one hand and of rights and duties on the other. Five possible strategies for advocates of the current international human right system seem to emerge from this: (1) top-down: the carrots and stick approach to convince all states of the current international normative system; (2) bottom-up: the soft power approach to convince local populations of the importance of individual rights and of the benefits of this system for their wellbeing; (3) emphasizing those elements of international human rights in domestic discourses that are closer to moral principles, i.e. that are less value laden; (4) extending the margin of appreciation for the interpretation of international human rights norms to facilitate the ease of which the previous three strategies can lead to a greatest common denominator; (5) providing alternative legal mechanisms concerning the right-duty and the individual-group-state relationship.

\section{Acknowledgments}

The author is in debt to the VIEW group, Christopher Lamont and Joris Kocken as well as the reviewers for their invaluable comments.

ives/sum2011/entries/morality-definition (accessed on 25 November 2012).

2. Paine T. Rights of Man. Hertfordshire, UK: Wordsworth Editions; 1996. p. 33.

3. For example, the philosophies of: Thomas Aquinas, Francisco Suárez, Thomas Hobbes, Hugo Grotius, Samuel von Pufendorf, John Locke, Francis Hutcheson, and Emmerich de Vattel.

4. Gardner J. Simply in Virtue of Being Human: 
The Whos and Whys of Human Rights. Journal of Ethics \& Social Philosophy. 2008;2(2):1-22.

5. Talbott W. Which Rights Should Be Universal? Oxford, UK: Oxford University Press; 2005.

6. Shue H. Basic Rights: Subsistence, Affluence, and U.S. Foreign Policy. Princeton, NJ, USA: Princeton University Press; 1996. pp. 29-34.

7. Dreier H. Gustav Radbruch und die Mauerschtützen. Juristen Zeitung. 1997;52(9):421-434.

8. Hart HLA. Positivism and the Separation of Law and Morals. Harvard Law Review. 1958;71(4):594.

9. Kelsen H. Was ist Gerechtigkeit? Stuttgart, Germany: Reclam; 2000.

10. Sharma A. Are Human Rights Western? Oxford, UK: Oxford University Press; 2006.

11. Tharoor S. Are Human Rights Universal? World Policy Journal. 1999/2000;16(4):1-6.

12. Brems E. Human Rights: Universality and Diversity. The Hague, The Netherlands: Martinus Nijhoff Publishers; 2001.

13. "The term 'margin of appreciation' refers to the latitude a government enjoys in evaluating factual situations and in applying the provisions enumerated in international human rights treaties." Arai-Takahashi Y. The Margin of Appreciation Doctrine and the Principle of Proportionality in the Jurisprudence of the ECHR. Antwerp, Belgium: Intersentia; 2002. p. 2.

14. Baderin MA. International Human Rights and Islamic Law. Oxford, UK: Oxford University Press; 2003.

15. Al-Jabri MA. Democracy, Human Rights and Law in Islamic Thought. London, UK: I B Tauris; 2009.

16. Mayer $\mathrm{AE}$. Cultural particularism as a bar to women's rights: Reflections on the Middle Eastern experience. In: Peters JS, Wolper A, editors. Women's rights, human rights: International feminist perspectives. New York, NY, USA: Routledge; 1995. pp. 176-188.

17. Bakhtiar L. Encyclopedia of Islamic Law-A Compendium of the Major Schools. Chicago, IL, USA: ABC International Group; 1996. pp. 229-241.

18. Donnelly J. Human Rights and Human Dignity: An Analytic Critique of Non-Western Conceptions of Human Rights. American Political Science Review. 1982;76(2):303-316.

19. BverfG. 1 BvR 357/05. 15 February 2006. Para. (1-156):131. Available from: http://www.bverfg. de/entscheidungen/rs20060215_1bvr035705.html (accessed on 25 November 2012).

20. Debatte über Flugzeug-Abschuss: Die Scheinwelt eines Verteidigungsministers. Spiegel Online. Available from: http://www.spiegel.de/politik/deutsch land/0,1518,506562,00.html (accessed on 25 November 2012).

21. "Preference is given to the positive law, duly and secured by state power as it is, even when it is unjust and of no benefit to the people, unless its conflict with justice reaches so intolerable a level that the statute becomes, in effect, 'false law' and must therefore yield to justice" ("Der Konflikt zwischen der Gerechtigkeit und der Rechtssicherheit dürfte dahin zu lösen sein, daß das positive, durch Satzung und Macht gesicherte Recht auch dann den Vorrang hat, wenn es inhaltlich ungerecht und unzweckmäßig ist, es sei denn, daß der Widerspruch des positiven Gesetzes zur Gerechtigkeit ein so unerträgliches $M a ß$ erreicht, daß das Gesetz als , unrichtiges Recht' der Gerechtigkeit zu weichen hat"). Radbruch G. Gesetzliches Unrecht und übergesetzliches Recht. Schweizerische Juristen-Zeitung/Revue Suisse de Jurisprudence. 1946:107. In: Radbruch G. Gesamtausgabe. Vol. 3. Heidelberg, Germany: Müller, Juristischer Verlag; 1988. p. 89. Translated in: Paulson SL. Radbruch on Unjust Laws: Competing Earlier and Later Views? Oxford Journal of Legal Studies. 1995;15(3):490.

22. Dreier H. Gustav Radbruch und die Mauerschützen. Juristen Zeitung. 1997;52(9):427.

23. K.-H. W. v. Germany (Berlin Border Guard Case). European Court of Human Rights (Grand Chamber). Application no. 37201/97. Judgment on the Merits (22 March 2001).

24. Landesgericht Frankfurt am Main. Press Release: Schriftliche Urteilsgründe in der Strafsache gegen Wolfgang Daschner. 15 February 2005. Available from: http://www.lg-frankfurt.justiz.hessen.de/irj/servl et/prt/portal/prtroot/slimp.CMReader/HMdJ_15/LG_Fr ankfurt_Internet/med/acb/acb50880-b973-6411-aeb6df144e9169fc, 222222222-2222-2222-2222-222222222 222,true.pdf (accessed on 25 November 2012).

25. For a collection of links to the German press covering this topic in the aftermath of the Daschner trial see: http://www.stop-torture.de/presse.html and http://www.stop-torture.de/presse-neu.html.

26. Donnelly J. International Human Rights. 3rd ed. Boulder, Colorado, USA: Westview Press; 2007. p. 37.

27. Renteln $A D$. International Human Rights: Universalism versus Relativism. Newbury Park, CA, USA: Sage; 1990. pp. 69-72.

28. Schmidt PF. Some Criticism of Cultural Relativism. Journal of Philosophy. 1955;52(25):780-791.

29. Donnelly J. Universal Human Rights: In Theory and Practice. 2nd ed. New York, NY, USA: Cornell University Press; 2003. p. 91.

30. Hume D. An Enquiry Concerning the Principles of Morals. Indianapolis, IN, USA: Hackett Publishing; 1983.

31. Kant I. Kritik der reinen Vernunft. Ditzingen, Germany: Reclam; 1986.

32. Smith A. The Theory of Moral Sentiments. Mineola, NY, USA: Dover Publications; 2006.

33. Donnelly J. Cultural Relativism and Universal Human Rights. Human Rights Quarterly. 1984;6(4): 415.

34. Donnelly J. The Relative Universality of Human 
Rights. Human Rights Quarterly. 2007;29(2):281-306.

35. Goodhart M. Neither Relative nor Universal: A Response to Donnelly. Human Rights Quarterly. 2008; 30(1):183-193.

36. Donnelly J. Human Rights: Both Universal and Relative (A Reply to Michael Goodhart). Human Rights Quarterly. 2008;30(1): 194-204.

37. Gert B. Common Morality: Deciding what to do. New York, NY, USA: Oxford University Press; 2004.

38. Lewis CS. The Abolition of Man. New York, NY, USA: HarperCollins Ebooks; 2001. pp. 83-101.

39. The law of Mercy is one of the best counter examples for the evolutionary theory of morality that claims that moral behaviour developed out of the need to cooperate to better survive. Because the criterion of survival of a group is violated by taking care of lethally wounded and deadly sick-they would only drain valuable resources and do not give any benefits to the group. The only explanation could be to say that those taking care could hope for the same treatment, but then again they would have to be afraid of defectors. In this case defection is particularly plausible because no emotional bond (such as between parents and children) of reciprocity exists.

40. For example, a child hitting its mother has a different moral quality than a person hitting a stranger.

41. Cavallar G. The Rights of Strangers: Theories of International Hospitality, The Global Community and Political Justice since Vitoria. Aldershot, UK: Ashgate; 2002.

42. Linklater A. The Problem of Harm in World Politics. Cambridge, UK: Cambridge University Press; 2011. p. 105.

43. Maslow A. A theory of human motivation. Psychological Review. 1943;50:370-396. Classics in the History of Psychology. Available from: http://psych classics.yorku.ca/Maslow/motivation.htm (accessed on 25 November 2012).

44. Gurr TR. Why men rebel. Princeton, NJ, USA: Princeton University Press; 1970. pp. 25-26.

45. Deci EL, Ryan RM. The 'What' and 'Why' of Goal Pursuits: Human Needs and the Self-Determination of Behavior. Psychological Inquiry. 2000;11(4): 227.

46. One should mention that "self-transcendence: to connect to something beyond the ego or to help others find self-fulfilment and realize their potential" is frequently included in the hierarchy but is not found in Maslow's original article on human motivation. See: Huitt W. Maslow's hierarchy of needs. Educational Psychology Interactive. Valdosta State University. 2004. Available from: http://www.edpsycinteractive.org/topi cs/conation/maslow.html (accessed on 25 November 2012). The hierarchical structure of these needs has been doubted by Maslow himself and is frequently disputed. See for example: Wahba MA, Bridwell LG. Maslow Reconsidered: A Review of Research on the
Need Hierarchy Theory. Organizational Behavior and Human Performance. 1976;15(2):212-240.

47. In accordance with statutory domestic and Sharia law the crimes of murder and robbery could be punished by death, and theft according to Sharia law would be punishable by cutting off limbs. See: Jok AA, Leitch RA, Vandewint C. A Study of Customary Law in Contemporary Southern Sudan. World Vision International and the South Sudan Secretariat of Legal and Constitutional Affairs. 2004. Available from: http://site resources.worldbank.org/INTJUSFORPOOR/Resources /JoketalStudyofCustomaryLawinContemporarySouthSu dan.doc (accessed on 25 November 2012).

48. Hudson WD. Modern Moral Philosophy. 2nd ed. New York, NY, USA: Palgrave Macmillan; 1983.

49. Shackelford TK. An Evolutionary Psychological Perspective on Cultures of Honor. Evolutionary Psychology. 2005;3:381-391.

50. Ahmed A. Journey into Islam: The Crisis of Globalization. Washington, DC, USA: Brookings Institution Press; 2009.

51. Yamamoto T. Hagakure-Der Weg des Samurai. Kabel, Germany: 2007. pp. 164-166.

52. Human Rights Committee (CCPR). General Comment No. 20. Replaces general comment 7 concerning prohibition of torture and cruel treatment or punishment (Art. 7). 03/10/1992.

53. Human Rights Committee (CCPR). General Comment No. 07. Torture or cruel, inhuman or degrading treatment or punishment (Art. 7). 05/30/1982.

54. Habermas J. Moral Consciousness and Communicative Action. Cambridge, MA, USA: Polity Press; 1993.

55. Ludwig Wittgenstein. Philosophical Investigations. Oxford, UK: Blackwell; 1986.

56. Lamm C, Batson CD, Decety J. The Neural Substrate of Human Empathy: Effects of PerspectiveTaking and Cognitive Appraisal. Journal of Cognitive Neuroscience. 2007;19(1):42-58.

57. Preston SD, de Waal FBM. Empathy: Its Ultimate and Proximate Bases. Behavioral and Brain Sciences. 2002;25:1-72.

58. Decety J, Jackson PL. The Functional Architecture of Human Empathy. Behavioral and Cognitive Neuroscience Reviews. 2004;3(2):71-100.

59. Cheng $Y$, Yang $C Y$, Lin $C P$, Lee PL, Decety J. The Perception of Pain in Others Suppresses Somatosensory Oscillations: A Magnetoencephalography Study. NeuroImage. 2008;40(4):1833-1840.

60. Gallese V. The 'Shared Manifold' Hypothesis: From Mirror Neurons to Empathy. Journal of Consciousness Studies. 2001;8(5-7):33-50.

61. Botvinick M, Jha AP, Bylsma LM, Fabian SA, Solomon PE, Prkachin KM. Viewing Facial Expressions of Pain Engages Cortical Areas Involved in the Direct Experience of Pain. NeuroImage. 2005;25(1):312319. 
62. Silber JR. Kant's Conception of the Highest Good as Immanent and Transcendent. The Philosophical Review. 1959;68(4):469-492.

63. Williams BAO. In the Beginning was the Deed: Realism and Moralism in Political Argument. Princeton, NJ, USA: Princeton University Press; 2005. pp. 21-23. 64. Hodgson L-P. Kant on the Right to Freedom: A
Defense. Ethics. 2010;120(4):791-819.

65. Marty D. Committee on Legal Affairs and Human Rights. Alleged Secret Detentions and Unlawful Inter-State Transfers Involving Council of Europe Member States. Council of Europe. AS/Jur (2006). 16 Part II 7 June 2006. 